\title{
Pengembangan Internal Locus of Control dalam Pelayanan Konseling dan Implikasinya terhadap Perbedaan Budaya Klien
}

\author{
Marjohan ${ }^{1}$ \\ ${ }^{1}$ Fakultas Ilmu Pendidikan, Universitas Negeri Padang
}

\begin{abstract}
The goal of counseling, among other thing, is to develop an internal locus of control of a clients. Research, especially in western cultures, has shown that those with an internal locus of control were correlated to their characters, they are: hard work, problem solving skilss, optimistic, engaging in social activities and high in achievement motivation. However, for clients who are not from western cultures a tendency to foster an internal locus of control in the counseling process should be considered properly. This paper describes how to enhance client's internal locus of control for those who do not embrace western cultures
\end{abstract}

Keyword: Locus of Control, budaya, konseling

Copyright (C) 2013 IICE - Multikarya Kons (Padang - Indonesia) dan IKI - Ikatan Konselor Indonesia - All Rights Reserved Indonesian Institute for Counseling and Education (IICE) Multikarya Kons

\section{PENDAHULUAN}

Pelayanan konseling telah lama dipandang oleh para ahli sebagai bagian yang tak terpisahkan dalam sistem pendidikan di sekolah dan didisain untuk membantu peserta didik mengembangkan wawasan, pengetahuan, keterampilan, nilai dan sikap berkenaan dengan diri dan lingkungannya sehingga potensi mereka dapat berkembang secara optimal (Prayitno dan Erman Amti, 1994; Shertzer \& Stone, 1980). Pentingnya layanan konseling ini dalam sebuah sistem pendidikan juga diakui oleh para pendidik. Gibson \& Mitchel (1990) misalnya, menyatakan bawa kehadiran layanan konseling pada program sekolah merupakan kemajuan dan salah satu karakteristik dari sistem pendidikan di berbagai negara saat ini. Di Indonesia, pentingnya layanan konseling tersebut juga dapat dilihat dari berbagai aturan dan perundang-undangan pendidikan di Indonesia. Peraturan Menteri Pendidikan Nasional (Permendiknas) No. 22 tahun 2006 tentang Standar Isi menyatakan bahwa pelayanan konseling di sekolah/madrasah merupakan usaha membantu peserta didik dalam pengembangan kehidupan pribadi, kehidupan sosial, kegiatan belajar, serta perencanaan dan pengembangan karir. Pelayanan konseling memfasilitasi pengembangan peserta didik, secara individual, kelompok dan atau klasikal, sesuai dengan kebutuhan, potensi, bakat, minat, perkembangan, kondisi, serta peluang-peluang yang dimiliki. Pelayanan ini juga membantu mengatasi kelemahan dan hambatan serta masalah yang dihadapi peserta didik. Selanjutnya dalam Permendiknas itu juga dinyatakan bahwa yang dimaksud dengan pelayanan konseling adalah pelayanan

\footnotetext{
* Telp atau Alamat Email Koresponden :

${ }^{1}$ E-mail address: marjohanful@gmail.com
} 
bantuan untuk peserta didik, baik secara perorangan maupun kelompok, agar mampu mandiri dan berkembang secara optimal, dalam bidang pengembangan kehidupan pribadi, kehidupan sosial, kemampuan belajar, dan perencanaan karir, melalui berbagai jenis layanan dan kegiatan pendukung, berdasarkan norma-norma yang berlaku.

Salah satu upaya dalam membantu kemandirian dan perkembangan optimal peserta didik dalam kehidupan mereka adalah pengembangan locus of control mereka. Locus of control merupakan konsep yang dikemukakan oleh Julian F. Rotter (1966) yang menjelaskan sejauh mana individu meyakini bahwa perilaku mereka menentukan apa yang akan terjadi pada diri mereka. Dia menegaskan bahwa kualitas atau derajat seseorang mengontrol berbagi kejadian dalam hidupnya akan mempengaruhi keputusan yang akan diambilnya dan interaksinya dengan orang lain. Lefcourt (1982) menyatakan bahwa individu perlu efektif dan menyadari diri mereka serta akan menjadi penentu terhadap nasib mereka. Pelayanan konseling, khususnya di dunia barat, selama ini lebih banyak mengarahkan perhatiannya untuk membantu para klien untuk menjadi pribadi yang mandiri, tidak menyerah pada nasib dan idividu yang mampu mengatasi masalahnya dengan tidak tergantung kepada orang lain. Ada semacam tradisi pada teori-teori konseling di dunia barat yang menghargai nilai-nilai otonomi, individualisme, kompetisi dan sejenisnya dalam kehidupan.

Bagaimanapun juga perlu dipahami bahwa bagi individu yang hidup di negara-negara yang tidak dibesarkan dalam budaya barat di atas, agaknya penghargaan yang tinggi terhadap budaya individualisme, kompetisi dan otonomi belum menjadi pandangan hidup mereka yang dominan dan bahkan tidak cocok dengan pandangan seperti itu. Speight, et al., (1991: 29) menyatakan "all humans differ in terms of cultural background, values or life style". Ide ini juga diakui oleh Pedersen (1991) yang menyatakan sebelum seseorang lahir ke dunia, pola-pola pikir dan cara-cara bagaimana seseorang mestinya bertingkah laku telah disiapkan oleh orang tua dan masyarakat sekeliling mereka. Pola pikir dan cara-cara bertingkah laku itu akan menjadi pedoman bagi individu untuk hidup sejahtera di lingkungannya. Konsekuensinya, konselor perlu menyadari perbedaan nilai yang dibawa klien dan memahami dengan baik bagaimana budaya mereka tersebut mempengaruhi tingkah laku dan keputusan yang mereka ambil sehari-hari. Dalam kaitan ini Pedersen (1988) menyatakan: Understanding group differences, as well as individual differences, is important to the accurate interpretation of behaviors. Counseling strategies that disregard the influence of a client's cultural context are unlikely to interpret a client's behavior accurately (p. vii).

Dengan demikian upaya-upaya atau strategi yang diterapkan dalam layanan konseling yang tidak didasarkan kepada pemahaman terhadap budaya klien akan membuahkan interpretasi yang salah tentang perilaku mereka dan tentu saja akan mengakibatkan pelayanan tersebut tidak efektif

\section{KAITAN ANTARA BUDAYA DAN KONSELING}

Kaitan antara budaya dengan konseling telah diakui oleh sejumlah ahli. Wacana tentang budaya serta pentingnya dalam pelayanan konseling telah banyak mendapat perhatian dalam berbagai literatur (lihat Hill, 1994; Lee, 1984; Pedersen, 1988; Ridley, et al., 1994; dan Sue \& Sue, 1990). Berbagai isu berkenan dengan konsep budaya, seperti masalah etnis, ras, pandangan hidup, dan sebagainya telah banyak diteliti oleh para penulis dalam bidang konseling. Semua wacana itu berkisar dalam suatu tema yang sering dikenal dengan konseling multi budaya (multicultural counseling). 
Ada sejumlah alasan mengapa konsep-konsep tentang budaya perlu dipertimbangkan dalam pelayanan konseling. Pertama, konseling tidak terjadi dalam keadaan kosong yang terpisah dari pengaruh sosial budaya masyarakat sekitarnya (Sue \& Sue, 1990). Pedersen (1985) menegaskan bahwa "culture is a frame of reference from which we encounter the world, ourselves, and life" (p.6). Karenanya, profesi konseling dipengaruhi oleh kerangka sosial budaya setempat. Kedua, seluruh manusia berbeda dalam hal latar belakang budaya, nilai-nilai yang dianut, atau gaya hidupnya. Oleh karena itu seluruh layanan konseling perlu bersifat lintas budaya atau multi budaya (Ibrahim, 1991; Pedersen, 1990; Speight, et al., 1991). Pemikiran ini didasarkan atas keyakinan bahwa setiap hubungan dalam konseling melibatkan dua atau lebih peserta yang berbeda latar belakang budaya, nilai, dan gaya hidupnya (Sue \& Sue, 1990). Dengan demikian, pemahaman budaya sebagaimana halnya dengan pemahaman perbedaan individu merupakan hal yang penting dalam hubungan konseling (Pedersen, 1988). Ketiga, secara luas disadari bahwa individu berbeda dalam hal sikap budaya, nilai, dan keyakinan yang membentuk keunikan mereka dalam memandang kehidupan (Schwebel, 1980; Sue \& Sue, 1990; Sundberg, 1981). Pandangan hidup yang dianut manusia secara langsung mempengaruhi sistem kepercayaan, asumsi, cara-cara penyelesaian masalah, pengambilan keputusan, dan pemecahan konflik-konflik mereka (Ibrahim, 1991). Oleh karenanya, adalah penting sekali bagi konselor untuk memahami pandangan hidup kliennya. Keempat, karena keefektifan konseling tergantung kepada pemahaman klien sebagai individu yang unik, konselor perlu mengaitkan pengalaman-pengalaman individu yang unik itu sebagai akibat dari proses budaya (Ridley, at al., 1994). Oleh karena itulah mengapa perlu sekali konselor, dalam rangka memahami secara penuh tingkah laku manusia, perlu memahaminya dari sudut konteks sosial budaya (Segall, et al., 1990). Atas alasan-alasan ini, dapat disimpulkan bahwa pemahaman budaya manusia akan memperjelas pemahaman konselor terhadap perilakunya dan perilaku orang lain dan akan menggiring mereka untuk bertindak secara efektif dalam hubungan konseling.

Menurut Carter (1991), Ibrahim (1991), Hui \& Triandis (1986) dan Sue \& Sue (1990), ada dua variabel penting yang perlu diperhatikan konselor ketika ia melaksanakan interaksi dalam hubungan konseling. Kedua variabel itu adalah nilai budaya atau pandangan hidup klien dan dimensi individualisme-kolektivisme klien.

Pandangan hidup yang dianut klien adalah komponen penting dari keperibadian individu yang perlu diperhatikan oleh konselor dalam hubungan konseling. Ibrahim (1991) menegaskan bahwa konseling multi budaya akan dapat menjadi kehilangan makna kecuali bila konselor dapat menggunakan pandangan hidup klien sebagai variabel antara dalam setiap kekhususan pertemuan konseling. Dia menambahkan bahwa pandangan hidup yang dimiliki klien merupakan suatu mekanisme bagi konselor dan klien untuk memahami bagaimana etnis, budaya, sejarah sosial dan politik, dan gaya hidup mempengaruhi pilihan-pilihan hidup dan kemampuan pengambilan keputusan. Lebih lanjut Sue \& Sue (1990) mengemukakan bahwa pandangan hidup yang dimiliki seseorang tidak hanya menyumbang kepada sikap, nilai, pendapat, dan konsepnya, tetapi juga dapat mempengaruhi bagaimana mereka berpikir, membuat keputusan dan menjelaskan kejdian-kejadian baik yang dialaminya atau yang dilihatnya.

Dimensi individualisme dan kolektivisme juga merupakan aspek penting lain yang dapat digunakan konselor dalam memahami budaya klien (Hui \& Triandis, 1986; Triandis, 1989). Menurut Hui dan Triandis (1986), dimensi individualisme dan kolektivisme dapat dilihat sebagai variabel budaya sebagaimana halnya dengan variabel keperibadian. Sebagai suatu variabel budaya, individualisme dan kolektivisme berbeda dalam beberapa hal. Ada sejumlah karakteristik individu yang berada dalam dimensi kolektivisme, seperti (1) memberikan pertimbangan bahwa implikasi keputusan atau tindakan yang diambilnya pada orang lain, (2) berbagi dalam hal sumber-sumber materi (3) berbagi dalam hal sumber-sumber non materi (4) rentan terhadap pengaruh-pengaruh sosial; (5) berbagi akibat-akibat seperti penderitaan atau kebahagiaan, dan (6) perasaan terlibat dalam kehidupan orang (Hui \& Triandis, 1986, p. 229-232). 
Dari sudut pandangan Hui and Triandis, adalah bisa dimengerti untuk memprediksi bagaimana pandangan hidup mereka yang kolektivis dibandingkan dengan yang individualis. Orang-orang yang berpandangan kolektivisme cenderung mengambil keputusan atas dasar pandangan apakah tindakan mereka menguntungkan keluarga, atau anggota kelompoknya. Mereka juga cenderung menjaga hubungan sosial mereka dengan cara meminjamkan, meminjam, memberikan harta mereka pada yang lain, berbagi rasa, patuh terhadap norma kelompok, dan menunjukkan kepedulian yang amat dalam terhadap penerimaan kelompok. Mereka juga merasa bahwa apa bila mereka gagal atau bertindak tidak tepat hal itu akan mendatangkan malu kepada keluarga atau kelompok mereka. Para kolektivis juga percaya bahwa kehidupan orang lain dapat berpengaruh langsung atau tidak kepada kehidupannya (Hui \& Triandis, 1986).

Sebaliknya, Hui dan Triandis mencatat bahwa karakteristik kolektivisme di atas tidak didukung oleh mereka yang beraliran individualisme. Lebih lanjut dikemukakannya, karena individualisme merasa dan berpikir bahwa mereka mampu mengurus diri mereka, mereka memberi nilai tinggi pada kebebasan dan kecukupan diri sendiri, dan kurang peduli pada orang lain.

\section{PENGEMBANGAN INTERNAL LOCUS OF CONTROL KLIEN DALAM LAYANAN KONSELING LINTAS BUDAYA}

Locus of control merupakan konsep nilai yang pertama kali diperkenalkan oleh Rotter (1966). Dia menjelaskan konsep tersebut sebagai sejauhmana individu memahami dirinya dalam kaitannya dengan kemampuannya dalam mengendalikan atau mengontrol lingkungan. Lebih lanjut dikemukakannya bahwa individu menginterpretasikan peristiwa-peristiwa atau hasil-hasil yang diperolehnya dalam dua cara, yaitu melalui kontrol yang bersifat internal (internal locus of control) dan kontrol yang bersifat eksternal (external locus of control). Apabila mereka meyakini bahwa suatu peristiwa atau hasil dari suatu tindakan merupakan akibat dari nasib baik, kebetulan, nasib atau kekuatan orang lain, mereka dikategorikan kepada external locus of control. Sebaliknya jika individu menginterpretasikan bahwa peristiwa atau apa yang mereka dapatkan sekarang adalah akibat dari kemampuan atau usaha mereka sendiri, mereka itu digolongkan sebagai individu yang memiliki internal locus of control.

Para ahli tampaknya sangat mendorong upaya-upaya untuk mengembangkan pribadi individu untuk memiliki sifat-sifat yang mengarah kepada internal locus of control. Sejumlah penelitian menunjukkan hubungan antara derajat locus of control yang dimiliki remaja dengan berbagai aspek kehidupannya. Lefcourt dan Rotter (dalam Sue \& Sue, 1982) menyimpulkan temuan-temuan penelitian berkaitan dengan locus of control yaitu internal locus of control berkorelasi dengan (1) kerja keras menguasai lingkungan, (2) keterampilam dalam menemukan strategi pemecahan masalah, (3) lebih baik dalam memproses informasi, (4) rendah kecenderungan untuk merasa cemas, (5) tinggi motivasi berprestasi, (6) lebih banyak terlibat dalam kegiatan sosial, dan (7) memberikan penghargaan yang tinggi terhadap penguasaan keterampilan. Selanjutnya Dalley, et al, 1992; Powell, Denton, \& Matson, 1995 menemukan bahwa remaja yang cenderung memiliki internal locus of control, dibandingkan teman-temannya yang external locus of control, menunjukkan karakteristik lebih banyak terhindar dari depresi, tidak mau menggunakan obat-obat terlarang, memperoleh prestasi belajar yang bagus untuk semua tingkat kelas di SMA, cenderung menjadi pemimpin dalam kelompoknya, dan tidak terasing dari teman-temannya di sekolah atau di masyarakat. Selanjutnya Belle dan Burr (1991), Wintre dan Crowley (1993) melaporkan bahwa remaja yang mempunyai internal locus of control cenderung mengemukakan masalah-masalah pribadinya kepada orang lain dan datang meminta bantuan layanan konseling bila mereka membutuhkannya di banding mereka yang memiliki external locus of control. 
Pelayanan konseling yang berorientasi kepada pandangan hidup individualisme bertujuan untuk membantu para klien memiliki sifat dan karakteristik yang menggambarkan konsep nilai internal locus of control dimaksud (Trusty dan Lampe, 1997). Menurut Corsini dan Wedding, 1989) kebanyakan teori konseling melukiskan dan mengekplorasi persepsi yang dimiliki individu dan meningkatkan kontrol diri dalam rangka membantu mereka mengatasi masalahnya. Pendekatan konseling kognitif dan behavioral, misalnya upaya meningkatkan kontrol diri merupakan bagian yang tak terpisahkan dalam proses layanan konseling kedua pendekatan tersebut. Strong, Yoder dan Corcoran (1995) menegaskan bahwa upaya konselor dalam mendorong klien untuk memperkuat kekuatan dirinya adalah aspek fundamental dalam konseling, dan implikasinya adalah semua klien hendaknya diarahkan untuk berjuang memiliki internal locus of control. Malahan sejumlah ahli menyatakan bahwa meningkatkan internal locus of control klien adalah tujuan utama dari konseling (Frank, 1982: Strupp, 1970).

Kecenderungan untuk memberikan nilai yang tinggi pada internal locus of control sebagaimana dikemukakan di atas menurut Sue \& Sue (1982) adalah cerminan dari budaya Amerika yang mengagungkan " the uniqueness, independence, dan self-reliance pada setiap individu. Namun demikian bagi klien yang berasal bukan berasal dari budaya barat agaknya kecenderungan untuk memberikan harga yang tinggi pada internal locus of control dalam konseling seperti yang lazim berlaku di dunia barat perlu diteliti lebih lanjut.

Pada masyarakat yang berorientasi kolektivisme seperti Indonesia, Malaysia dan negara-negara timur lainnya, penekanan pada internal locus of control saja agaknya tidak sesuai dengan budaya mereka dan bahkan tidak produktif. Williams (2003) menyatakan strategi pelayanan konseling yang menyokong upaya-upaya kearah internal locus of control belum tentu cocok untuk masyarakat yang memakai pandangan hidup kolektivisme. Sebagaimana dikemukakan terdahulu masyarakat yang berbudaya kolektivisme lebih menekankan pentingnya keluarga atau kelompok dalam mengambil keputusan, dan dalam bertingkah laku. Seseorang yang lebih mementingkan kekuatan dirinya dalam bertindak dapat merupakan individu yang tidak diinginkan dalam masyarakat kolektivisme. Dengan demikian pribadi yang sehat dalam budaya kolektivisme adalah pribadi yang seimbang dalam memenuhi kebutuhan dirinya dengan kebutuhan keluarga atau kelompoknya. Dalam kaitan ini Marks (1998) menyatakan bahwa konselor mestinya menghindari menerapkan secara menyeluruh ide yang mengatakan bahwa internal locus of control selalu lebih baik dari external locus of control.

Dalam kaitan ini cara yang lebih bijak berkaitan dengan pengembangan internal locus of control dalam konseling pada klien-klien yang berorientasi kolektivisme ini adalah bahwa konselor perlu memperhatikan faktor etnis dan budaya klien, apakah konsep tersebut dapat membantu mereka mengembangkan berbagai potensi mereka atau bukan. Ada aspek dalam konseling yang perlu diperkuat internal locus of controlnya namun ada pula hal-hal yang menyangkut external locus of control yang perlu dipahami dan dimaknai secara positif oleh klien. Dalam kaitan ini kondisi dan peristiwa yang dialami klien yang berkaitan dengan upaya yang berhubungan dengan kemampuan atau usaha mereka sendiri, pengembangan internal locus of control klien oleh konselor dalam pelayanan konseling menjadi amat relevan. Tetapi apabila kondisi dan masalah yang dialami oleh klien berkaitan dengan peristiwa-peristiwa yang tak dapat dikendalikan klien seperti masalah yang tak diduga-duga atau kondisi insidental yang diyakini oleh klien sebagai suatu takdir yang berasal dari kemahakuasaan Tuhan, pengembangan internal locus of control pada diri klien tidak akan membuat mereka mengarah kepada kehidupan sehari-hari yang efektif dan produktif. Klien yang mengalami kasus-kasus seperti itu perlu didorong untuk mencari hikmah dibalik peristiwa atau kondisi insidental yang mereka alami itu sehingga dengan demikian mereka mampu memahami, menerima secara positif serta dapat mengambil berbagai langkah yang tepat untuk pengembangan diri mereka sewaktu menghadapi peristiwa dimaksud (Prayitno, 2004). 


\section{KEPUSTAKAAN}

Belle, D.; \& Burr, R. (1991). Why children do not confide: An exploratory analysis. Child Study Journal, 21, 217-233.

Carter, R.T. (1991). Cultural values: A review of empirical research and implications for counselling. Journal of Counseling \& Development, 70, 164-173.

Dalley, M.B; Bolocofsky, DN; Alcorn, M.B; \& Baker, C. (1992). Depressive symptomology, attributional style, dysfuncytional attitude and social competency in adolescents with and without learning disabilities school._Psychology Review, 21, 444-458.

Gibson, R.L., \& Mitchell, M.H. (1990). Introduction to counselling and guidance, (3rd Ed.). New York: Mc Millan Publishing Company.

Hill, C. (1991). Race/ethnicity in counseling process and measuring session outcome in counseling and psychotherapy. Journal of Counseling Psychology, 41, 123.

Hui, C.H., \& Triandis, H.C. (1986). Individualism-collectivism: A study of cross-cultural researchers. Journal of Cross-cultural Psychology, 17, 225-248.

Ibrahim, F.A. (1991). Contribution of cultural worldview to generic counseling and development. Journal of Counseling \& Development, 70, 13-19.

Lee, D.J. (1984). Counseling and culture: Some issues. The Personnel and Guidance Journal, 62, 592-597.

Lefcourt, H.M. (1982). Locus of control: Current trends in theory and research. New Jersey: Lawrence Erlbaum Associates, Publishers.

Pedersen, P.B. (1985). A Handbook of cross-cultural counseling and therapy. Westport, C.T: Greenwood Press.

Pedersen, P.B. (1988). A Handbook for developing multicultural awareness. Virginia: American Association for Counseling Development.

Pedersen, P.B. (1990). The multicultural perspective as a fourth force in counseling. Journal of Mental Health Counseling, 12, 93-95.

Pedersen, R.B. (1991) Multiculturalism as a generic approach to counseling. Journal of Counselling Development, 70, 6-12.

Peraturan Menteri Pendidikan Nsional No. 22 Tahun 2006 Tentang Standar Isi

Powell, J.W; Denton, R.; \& Mattson, A. (1995). Adolescent depresion: Effects of mutuality in the motheradolescent dyad and locus of control. American Journal of Orthopsychiatry, 65, 263-273.

Prayitno, \& Amti, E. (1994). Dasar-dasar bimbingan dan konseling. Jakarta: P3TK Direktorat Jenderal Pendidikan Tinggi, Departemen Pendidikan dan Kebudayaan R.I.

Ridley, C.R., Mendoza, D.W., Kanitz, B.E., Angermeir, L., \& Zenk, R. (1994). Cultural sensitivity in multicultural counseling: A perceptual schema model. Journal of Counseling Psychology, 41, 125136.

Rotter, J. (1966). Generalized expectations for internal versus external control of reinforcement. Psychological Monograph, 80, 1-28.

Schwebel, M. (1980). Epilogue: 2000 AD. In J.M. Whiteley \& B.F. Fretz (Eds.). The present and the future of counseling psychology. Monterey, California: Brooks/Cole.

Segall, M.H., Dason, P.R., Berry, J.W., Portinga, Y.H. (1990). Human behavior in global perspective : An introspection to cross-cultural psychology. New York: Pergamon.

Shertzer, B. \& Stone, S.C. (1980) Fundamental counseling (3rd.Ed.), Boston: Houghton Mifflin.

Speight, S.L., Myers, L.J., Cox, J.C., \& Highlen, P. (1991). A redefinition of multicultural counselling. Journal of Counselling and development, 70, 29-36.

Sue, D.W., \& Sue, D. (1990). Counseling the culturally different: Theory and practice. New York: John Wiley $\&$ Sons.

Sundberg, N.D. (1981). Cross-cultural counseling and psychotherapy: A research overview. In A.J. Mansella\& Pedersen (Eds.). Cross-cultural counseling and psychotherapy (pp.28-62). New York: Pergamon. 
Triandis, H.C. (1989). The self and social behavior in differing cultural contexts. Psychological Review, $\underline{96}$, 506-520.

Trusty, J., \& Lampe, R.E (1997). Relationship of high-school senior's perceptions of parental Involvement and control to seniors' locus of control. Journal of Counselling and development, 75, 375-384.

Williams, B. (2003). The worldview dimensions of individualism and collectivism: Implications for counseling. Journal of Counselling and development, 81, 370-374.

Wintre, M.G; \& Crowley, J.M. (1993). The adolescent of consultant preference. Journal of Youth and Adolescence, 22, 369-383. 